PROBLEMS

OF EDUCATION

IN THE $21^{\text {st }}$ CENTURY

Volume 42, 2012

74

\section{DIFFICULTIES OF UNDERGRADUATE STUDENTS IN THE ORGANIC CHEMISTRY} LABORATORY

\author{
Maria Gabriela Lorenzo, Ana Maria Reverdito, \\ Mercedes Blanco, Alejandra Salerno \\ University of Buenos Aires, Argentina \\ E-mail: glorenzo@ffyb.uba.ar, anarever@ffyb.uba.ar, \\ mblanco@ffyb.uba.ar, asalerno@ffyb.uba.ar
}

\begin{abstract}
Experimental work supposes a unique opportunity to learn procedural contents. However, the conditions and constraints to learn procedures have not been sufficiently discussed or investigated in a laboratory environment. Students' difficulties in organic chemistry laboratory at university are described and explained. A case study ( $n=15$ undergraduate students) was performed. The study was carried out in an actual laboratory class, using different ways for data gathering: 1) A comparison between declarative knowledge of students about experimental work and observations of procedures in class. 2) An evaluation of the effect of laboratory work on the knowledge of students related with the assembly of the apparatus. This research suggests that students' difficulties in performing experimental work are deeply related to a deficient interrelationship between conceptual and methodological frameworks.
\end{abstract}

Key words: experimental work, learning difficulties, organic chemistry laboratory, procedural contents, university.

\title{
Introduction
}

The knowledge about the different procedures at experimental work and difficulties for their learning would contribute to improve this kind of classes. In this work, we focused on the analysis of those procedures that allow the understanding of the learning difficulties that appear in the laboratory work of organic chemistry at university level. This work could provide strategies to improve those practices. If we attempt to imitate scientific work, laboratory work should provide opportunities to make a mistake, because science enterprise is much more that following a recipe book or using a certain technique.

\section{Problem of Research}

Laboratory work has been present in science education since the $19^{\text {th }}$ century. Until the 1980s, publications focused mainly on the advantages and limitations of the use of the laboratory for science instruction (Blosser, 1983, 1990). The high cost of materials, the demanded time by experimental work (De Jong, 1998, Insausti \& Merino, 2000), the lack of resources, health and safety risks, and the changing nature of the student population (Byers, 2002) were main limitations. Anyway, first-hand experience, observation and manipulation keep being very important for chemistry learning by students (Hofstein, 2004, Hofstein \& Mamlok-Naaman, 2007, Nakhleh, Polles, \& Malina, 2002).

A list of objectives for laboratory work had been already proposed by Shulman \& Tamir (1973) thinking on the students: 1) To achieve manipulative and intellectual skills, 2) To promote 
conceptual learning, 3) To develop cognitive abilities, 4) To understand the nature of science, and scientific working, 5) To encourage attitudes. From the teaching point of view there would be three objectives (Gupta, 2001, Seré, 2002): a) Teaching the experimental method (helping students to become familiar with the laboratory equipment and the measuring techniques, and training them in observation, and deduction, and writing reports); b) supporting to the theoretical information of the lectures by illustrating physical phenomena and concepts (practice in the service of theory); and c) affective goals that include scientific attitudes.

Most of the time, experimental methods in laboratory class do not often represent a challenge for students, because experimental classes primarily focus on lower-order cognitive skills. This "twisted vision" of scientific work comes from the scholastic culture. For many years, learning facts and concepts rather than developing skills have been emphasized (Reigosa \& Jiménez, 2000). Our previous investigations (Lorenzo \& Rossi, 2007) have shown that the primary instructor's goal was to consider experimental work like a teacher's tool for illustrating lectures and increasing students' interest.

Four different laboratory instruction styles have been described so far (Domin, 1999, 2007): expository, inquiry, discovery and problem-based. The expository laboratory class is focused in this paper because it is the most common type used at university; and because, it has been criticized by experts in science education (Byers, 2002, Hodson, 1994, 2005). Activities included in the expository (also termed traditional or verification) style typically follow a deductive approach and have predetermined outcomes. The procedure to be followed for any laboratory activity is always provided by the instructor, a laboratory manual, or a handout. Generally, instructors explain or demonstrate the experiment to students before they are allowed to perform it, and often expected outcomes are not discussed. However, many students try to obtain the data and then leave the lab as quickly as possible.

Using the same laboratory manual or handout with a classic expositive structure, diverse approaches to experimental work can be made (Jalil, 2006). Experience and practice are necessary to enable students to gain confidence for predicting and rationalizing reactivity at the molecular scale and to understand physical properties at the macroscopic level (Hassan, Hill, \& Reid, 2004).

\section{Research Focus}

The laboratory environment can be operationally labelled as those external influences that interact with the student during the learning process (Domin, 1999). Since this is full of rich information (Nakhleh, Polles, \& Malina, 2002), the nature of the environment not only determines what is learned or what must be learned, but also how it is learned. So, the effective thinking in laboratory is often inhibited by an excess of information that exceeds the limited working memory (Johnstone, 1993, Johnstone \& Al-Shuaili, 2001). The main difficulty of laboratory work is the narrow relationship between conceptual and procedural objectives that belong to theoretical and methodological framework respectively. For that reason, Seré (2002) suggests that it is advisable to reduce the conceptual load of laboratory work, in favour of process and epistemological-based work. Thus, if students have acquired procedures and methods, they could look for resolution of conceptual problems. Laboratory work can then be thought of as a progressive sequence from the observation of data to the elaboration of explanatory hypotheses (Reigosa \& Jiménez, 2000). In fact, laboratory work provides a spread of opportunities for students to learn techniques, make decisions, gain confidence, and make mistakes, plan experiments and record results, among others. Nevertheless, there is very little information about the difficulties in learning experimental work (Hunter, Mc Cosh, \& Wilkins, 2003) and about the role of laboratory in university chemistry (Reid \& Shah, 2007). Consequently, this work focuses on several aspects that have not yet been studied: The students'

$\mid$\begin{tabular}{l} 
PROBLEMS \\
OF EDUCATION \\
IN THE 21 $21^{\text {st }}$ CENTURY \\
Volume 42, 2012 \\
\hline 75
\end{tabular} 
PROBLEMS

OF EDUCATION

IN THE $21^{\text {st }}$ CENTURY

Volume 42, 2012

difficulties in organic chemistry laboratory. The main purpose of this research is to analyse the effect of laboratory work on the performance of students.

\section{Methodology of Research}

\section{General Background of Research}

A research in context (the real place where teachers and students perform their task) was carried out. In this case, an actual laboratory class in organic chemistry at university level was investigated. A qualitative approach (ethno-methodology) with non-participant observers, complemented with a quantitative approach applying statistical parameters, was used. The activity analysed was the assembly of the apparatus for the synthesis and isolation of an organic compound (butanal), which is made up of parts of apparatuses used by students in previous classes, and which is shown in the laboratory guide.

\section{Sample of Research}

Fifteen Argentine students of the School of Pharmacy and Biochemistry of the Buenos Aires University participated in this research.

\section{Instrument and Procedures}

In order to investigate the students' progress during the experimental work two tasks were carried out: 1) A comparison between declarative knowledge of students and observations of procedures in class. 2) A paper-and-pencil task (drawing task) to evaluate the effect of laboratory work on the knowledge of students about the assembly of the apparatus.

\section{Data Analysis}

\section{Task \#1. Comparison between declarative knowledge of students and observations in class}

A task of students' production and observations during the class were analysed at once. Students had to make a list of steps to follow during the laboratory work before assist the class. Three non-participant observers were present in the class in order to gather information: a) a general observation, in order to record non-anticipated events, and b) punctual observations with a guide focused on procedural contents on the assembly of the apparatus and the addition of reagents (i.e state the purpose of the practical work, select the volumetric material correctly, observe the steam ascent by the column, record the temperature, check the system, among others). Data from different sources (observations and students' list of steps) were concurrently analysed, with the individual and independent contributions of observers.

Task \#2. Effect of laboratory work on the assembly of the apparatus

Students were asked to draw the scheme of the apparatus for the laboratory work twice (figure 1): a) at the beginning of the class, before performing the experiment; $b$ ) after ending the experiment. Looking at the laboratory guide was not allowed. Each picture was then analysed to recognize different types of errors. Later, drawings were qualitatively compared in the two conditions (initial and final) for each student.

\section{Results of Research}

The analysis of the data collected from the students' list (task \# 1) showed their declarative knowledge (Zoller \& Pushkin, 2007). Students were able to enunciate some important 
procedures to consider during the practical work. For instance, they said they have to verify the apparatus once it is assembled and that they have to follow the security norms. Mainly, these statements agreed with the teacher's explanation and the laboratory guide. However, observations allowed us to detect some disagree with they can do, mistakes and difficulties throughout the experimental class. For example most of the students respect security norms but take too longer in the assembly of the apparatus for the synthesis, have difficulties in simple operations: do not select the materials completely, forget boiling chips, fit the metallic mesh erroneously, have difficulties in the selection and use of the volumetric material, and showed doubts about the sequence of steps. Other typical behaviour was the permanent claim for the teacher all along the practical work.

Task \# 2 revealed the impact of laboratory experience on students' working. Initial pictures (Figure 1) showed an important number of errors (64.2\%). The first-hand experience had a positive action on memory and learning; hence, after experimental work, the number of errors decreased, although it was still important (35.8\%). These outcomes illustrate difficulties with the interrelationship between conceptual and methodological frameworks because students did not understand the functions of the different parts of the equipment. Consequently, for example, some particular connectors were not taken into account.

The use of inappropriate materials (a single-necked round-bottomed flask), absence of connectors (thermometer inside of the fractionating column) or of certain specific parts (dropping funnel), and of supporting materials were common errors at the beginning. These errors were corrected in the second drawing, although some errors still persisted (alignment of the equipment). In some cases, twisted apparatuses or apparatuses without the appropriate proportions were observed. In general, connectors and supporting materials were omitted in the pictures.
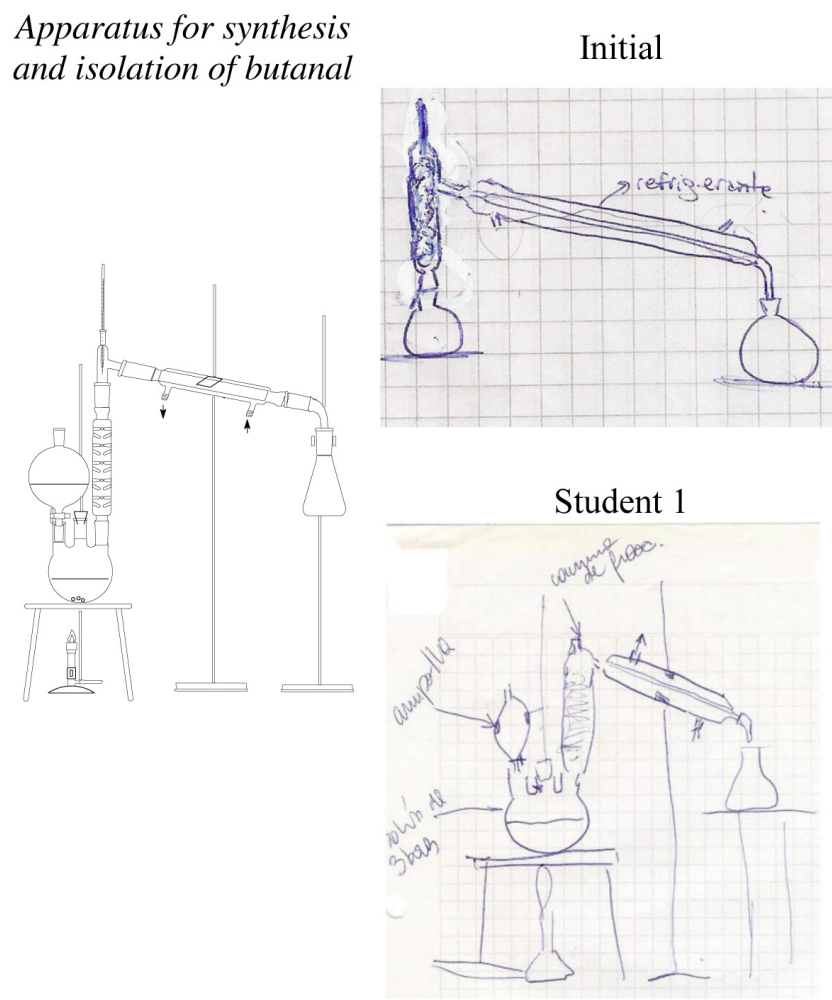

Student 2

\section{Final}

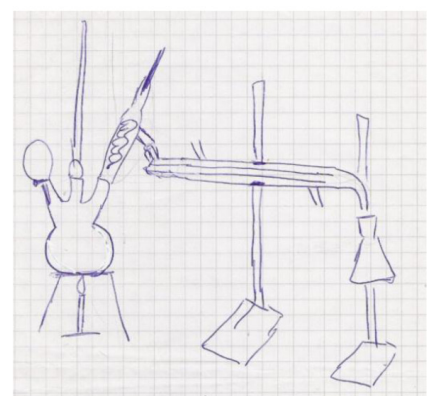

Student 1

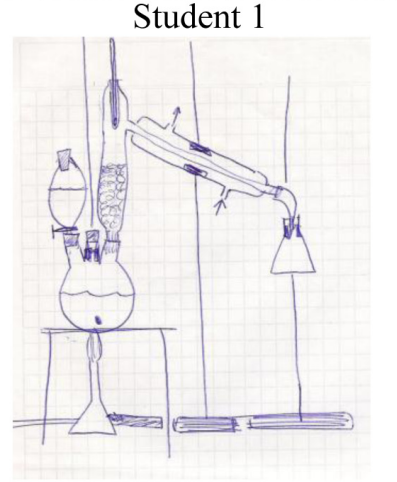

Student 2

Figure 1: Example of students' drawings compared with the given one. 


\section{PROBLEMS \\ OF EDUCATION \\ IN THE $21^{\text {st }}$ CENTURY \\ Volume 42, 2012 \\ 78 \\ Discussion}

The combination of the results obtained from the students' list and our observations allowed us to recognize differences between what 'students said' and what 'students performed' during the laboratory work. All the students required support of the teacher to progress with the development of the experimental work. Observations were categorized into four types:

I) Student performed what he/she said: In this case, there was a coincidence between the student's words and his/her work in the laboratory (genuine knowledge).

II) Student did not perform what he/she said: Particularly, the accurate assembly of the apparatus was an obstacle (methodological deficiency). Besides, important difficulties were observed respect to the "control" actions and the "recognition" of observable changes. When a student said "I'm controlling", he/she actually referred to an observation of effects. Students could not interpret observable effects as a consequence of the action applied on the system. Checking and correcting actions became difficult for students. Therefore, they could not take decisions and consequently, required external control (of the teacher) to carry out the practical work. All students resorted to the teacher and/or some class mate to face difficulties all throughout the practical class.

III) Student did not say but he/she was able to carry out the task: In this case, students knew how to do something but they did not know when, why or what for (conceptual deficiency). These actions were not anticipated on the students' list; however, they were able to carry out the task by themselves. This fact evidenced a poor interrelationship between methodological and conceptual frameworks (recording the temperature).

IV) Student neither said nor carried out the task: Associated procedures to the 'knowledge about practice' of methodological framework could not be anticipated by students. They showed problems for selecting the volumetric material. In addition, they showed insecurity about the sequence of steps to follow. So, they resorted repeatedly to reading the protocol of the technique throughout the experimental work. In the same way, they did not select the required materials in a complete way and forgot to add boiling chips into the flask. Consequently, they took longer in the assembly of the apparatus.

In all cases, guidance of the teacher was always required for students to perform certain actions such as controlling the dropping funnel and checking the temperature distillation. Students forgot the glass stopper and the receiver adapters or connectors for attachment to the end of the condensers, and to check the dropping funnel. However, since students immediately repaired those issues when the teacher told them to do so, this kind of situation was regarded as a difficulty in the theoretical framework. That is, students knew how to carry out the task, but did not know when or where they had to do.

In order to understand what goes on in laboratory classes to think on the constraints for learning procedures seems to be important. Laboratory work requires the knowledge about two big dimensions: theoretical and methodological frameworks. The results clearly show that students have difficulties in both aspects of experimental tasks. Although some suggestions on how to develop practical chemistry skill in laboratory classes have been made (Mc Donnell, O'Connor, \& Seery, 2007), they do not go deeper into the problem of learning the procedural contents.

Finally, assembly of apparatuses is a first obstacle for students trying to perform organic synthesis. Moreover, although several materials had been commonly used in a great number of equipments, the use of connectors or some accessories did not improve appreciably after practical work was achieved.

In order to organize laboratory work, a classification of procedural contents is proposed here for helping teachers. Two considerable groups of procedural contents in laboratory work have been previously reported (Lorenzo, Reverdito, Perillo, \& Salerno, 2001): sensor-motor 
procedures, which involve concrete actions (fitting the equipment, making measurements, preparing the reagents, etc.), and intellectual procedures, which include cognitive activities

PROBLEMS

OF EDUCATION

IN THE $21^{\text {st }}$ CENTURY

Volume 42,2012

(formulating hypotheses, making conclusions, taking decisions). Now, a deeper classification taking into account the purpose of laboratory procedures is proposed:

- Sensor-motor Procedures for Action: Fine motor skills for modification of the system (fit clamps, operate stopcock funnel, add boiling chips).

- Sensor-motor Procedures for Observation: Sense specialization (chemical eyes) for data gathering (see a change of colour or mercury column on the thermometer).

- Intellectual Procedures for Recognition: Interpretation of data for identification of certain macroscopic observable phenomena like indicators of events at submicroscopic level (read the temperature on the thermometer).

- Intellectual Procedures for Checking the experimental work: Strategic knowledge (planning, supervision and evaluation) for making a decision (verify water flow through the condenser, check the temperature of the system).

Whereas, the whole process in lab implies different kinds of procedural knowledge, it is necessary to find out how these different kinds of procedures interact in an experimental class. The above list would facilitate the scheduling of laboratory work.

\section{Conclusions}

There is a multiplicity of factors that take place when students perform an experimental work. This includes conceptual and methodological aspects, as well as their interrelationships. Special attention was required for simple everyday experimental work: selecting laboratory materials, assembling an apparatus, and using connectors. Student's attitudes to scientific work should be explicitly included as content in laboratory programs.

In order to perform these activities, students should know both conceptual and methodological frameworks in order to understand the foundations of their actions, and be able to control and evaluate their consequences.

This research suggests that students' difficulties in performing experimental work are deeply related to a deficient interrelationship between conceptual and methodological frameworks. So, when students knew what they should perform, they did not know how or they felt afraid to perform it. Although they had acquired some manipulative abilities in previous experiments, they did not know how to use those strategically. At university level, the fear to be wrong or hurt could play a negative role on students work.

All these aspects should be taken into account by science teachers. Chemistry teachers have the challenge to transform the laboratory in a real environment for learning. We thus need to improve experimental work neglecting technique recipes, in favour of constructing genuine knowledge.

\section{Acknowledgements}

This research work was supported by grants of the following Projects: UBACyT B20020100100010 and PIP-CONICET N 11220090100028 (2010-2012).

\section{References}

Blosser, P. (1983). What research says: the role of the laboratory in science teaching. School Science and Mathematics, 83, 165-169.

Blosser, P. (1990). The role of the laboratory in science teaching. Research Matters-to the Science Teacher $\mathrm{N}^{\circ}$ 9001. Retrieved 27/02/12, from http://www.narst.org/publications/research/labs.cfm 
PROBLEMS

OF EDUCATION

IN THE $21^{\text {st }}$ CENTURY

Volume 42,2012

Byers, W. (2002). Promoting active learning through small group laboratory classes. University Chemistry Education, 6, 28-34.

De Jong, O. (1998). Los experimentos que plantean problemas en las aulas de química: Dilemas y soluciones. Enseñanza de las Ciencias, 16 (2), 305-314.

Domin, D. (1999). A review of laboratory instruction styles. Journal of Chemical Education, 76 (4), 543-547.

Domin, D. (2007). Students' perceptions of when conceptual development occurs during laboratory instruction, Chemistry Education: Research and Practice, 8 (2), 140-152.

Gupta, V. (2001). Aims of laboratory teaching. CDTL Brief, 4 (1). Retrieved 17/01/2006, from http:// www.cdtl.nus.edu/brief/v4n1/default.htm

Hassan, A., Hill, R., \& Reid, N. (2004). Ideas underpinning success in an introductory course in organic chemistry. University Chemistry Education, 8, 40-51.

Hodson, D. (1994). Hacia un enfoque más crítico del trabajo de laboratorio. Enseñanza de las Ciencias, $12(3), 299-313$.

Hodson, D. (2005). Teaching and learning chemistry in the laboratory: A critical look at the research. Educación Química, 16 (1), 30-38.

Hofstein, A. (2004). The laboratory in chemistry education: thirty years of experience with developments, implementation and evaluation. Chemistry Education: Research and Practice, 5, 247-264.

Hofstein, A., \& Mamlok-Naaman, R. (2007). The laboratory in science education: the state of the art. Chemistry Education: Research and Practice, 8 (2), 105-107.

Hunter, C., Mc Cosh, R., \& Wilkins, H. (2003). Integrating learning and assessment in laboratory work. Chemistry Education: Research and Practice, 4 (1), 67-75.

Insausti, M. J., \& Merino, M. (2000). Una propuesta para el aprendizaje de contenidos procedimentales en el laboratorio de física y química. Investigações em Ensino de Ciências, 5 (2), 93-119. Retrieved 24/01/2012, from http://www.if.ufrgs.br/ienci/

Jalil, P. (2006). A procedural problem in Laboratory teaching: Experiment and explain, or vice-versa? Journal of Chemical Education, 83 (1), 159-163.

Johnstone, A. (1993). The development of Chemistry teaching. Journal of Chemical Education, 70 (9), 701-705.

Johnstone, A. H., \& Al-Shuaili, A. (2001). Learning in the laboratory; some thoughts from the literature. University Chemistry Education, 5, 42-51.

Lorenzo, M. G., Reverdito, A. M., Perillo, I., \& Salerno, A. (2001). Los contenidos procedimentales en el laboratorio de química orgánica para la formación docente. Revista de Educación en Ciencias, 2 (2), 102-105.

Lorenzo, M. G., \& Rossi, A. (2007). Experimental practical activities in scientific education. The Chemical Educator, 12, 1-6.

Mc Donnell, C., O’Connor, C., \& Seery, M. (2007). Developing practical chemistry skills by means of student-driven problem based learning mini-projects. Chemistry Education: Research and Practice, 8 (2), 130-139.

Nakhleh, M., Polles, J., \& Malina, E. (2002). Learning chemistry in a laboratory environment, In: J. K. Gilbert, O. De Jong, R. Justi, D. Treagust. (Eds) Chemical Education: Towards Research-based Practice, 47-68. Kluger Academic Publishers: The Netherlands.

Reid, N., \& Shah, I. (2007). The role of laboratory work in university chemistry. Chemistry Education: Research and Practice, 8 (2), 172-185.

Reigosa, C., \& Jiménez, M. P. (2000). La cultura científica en la resolución de problemas en el laboratorio. Enseñanza de las Ciencias, 18 (2), 275-284.

Séré, M. (2002). La enseñanza en el laboratorio. Qué podemos aprender en términos de conocimiento práctico y de actitudes hacia la ciencia? Enseñanza de las Ciencias, 20 (3), 357-368.

Shulman, L. S., \& Tamir, P. (1973). Research on teaching in the natural sciences." In R.M.W. Travers, (Ed.), Second handbook of research on teaching. Rand McNally. 
Maria Gabriela LORENZO, Ana Maria REVERDITO, Mercedes BLANCO, Alejandra SALERNO. Difficulties of Undergraduate Students in the Organic Chemistry Laboratory

Zoller, U., \& Pushkin, D. (2007). Matching Higher-Order Cognitive Skills (HOCS) promotion goals with problem-based laboratory practice in a freshman organic chemistry course. Chemistry Education: $\mid \begin{aligned} & \text { PROBLEMS } \\ & \text { OF EDUCATION } \\ & \text { IN THE } 21^{\text {st }} \text { CENTURY } \\ & \text { Volume 42, } 2012\end{aligned}$ Research and Practice, 8 (2), 153-171.

Advised by Naglis Švickus, SMC “Scientia Educologica”, Lithuania

Received: January 13, 2012

Accepted: March 07, 2012

\begin{tabular}{|ll|}
\hline Maria Gabriela Lorenzo & $\begin{array}{l}\text { Doctor, Director of CIAEC, Faculty of Pharmacy and Biochemistry, Univer- } \\
\text { sity of Buenos Aires, Junín } 956 \text { (1113) CONICET, Buenos Aires, Argentina. } \\
\text { E-mail: glorenzo@ffyb.uba.ar } \\
\text { Website: http://www.ffyb.uba.ar }\end{array}$ \\
\hline Ana Maria Reverdito & $\begin{array}{l}\text { Professor, Faculty of Pharmacy and Biochemistry, University of Buenos } \\
\text { Aires, Junín 956 (1113) CONICET, Buenos Aires, Argentina. } \\
\text { E-mail: anarever@ffyb.uba.ar }\end{array}$ \\
Mercedes Blanco & $\begin{array}{l}\text { Doctor, Faculty of Pharmacy and Biochemistry, University of Buenos Aires, } \\
\text { Junín 956 (1113) CONICET, Buenos Aires, Argentina. }\end{array}$ \\
E-mail: mblanco@ffyb.uba.ar \\
\hline Alejandra Salerno & $\begin{array}{l}\text { Doctor, Faculty of Pharmacy and Biochemistry, University of Buenos Aires, } \\
\text { Junín 956 (1113) CONICET, Buenos Aires, Argentina. } \\
\text { E-mail: asalerno@ffyb.uba.ar }\end{array}$ \\
\hline
\end{tabular}

